\title{
Risk Factors for the Transmission of Mycobacterium Bovis to Slaughterhouses Workers in Brazzaville, Republic of the Congo
}

Jean P. Miassangoumouka

IRA

Laure S. Ghoma Linguissi

IRSSA

Lauréat Pavel Itoua

IRA

Brigitte Tumamo Fotso

FCRM

Geneviève Andoseh

FCRM

Leonard Numfor

FCRM

Inestin Amona

iRSSA

Hortense Goma Kikayi

IRSSA

Francine Ntoumi ( $\nabla$ ffntoumi@hotmail.com )

Fondation Congolaise pour la Recherche Médicale

Research article

Keywords: Slaughterhouses, workers, risks, tuberculosis, Brazzaville

Posted Date: September 25th, 2020

DOl: https://doi.org/10.21203/rs.3.rs-55319/v1

License: (1) (i) This work is licensed under a Creative Commons Attribution 4.0 International License.

Read Full License 


\section{Abstract}

Zoonotic tuberculosis is a major form of TB affecting humans and many animal species. Infected cattle pose a threat to public health. The aim of the study was to characterize the risks of exposure to bovine tuberculosis by slaughterhouse workers in Brazzaville. A survey was carried out among 57 workers from three slaughterhouses in Brazzaville (Mpila, Kanga Mbanzi and La Fougère) using questionnaires and field observations. The results of the profile revealed that the majority of staff are made up mainly of people over 40 years old $(40.6 \pm 8.4)$ i.e. $50.9 \%$ and $96.5 \%$ male. Married workers represent a third of respondents $(29.8 \%)$ and live in families made up of $4.9 \pm 2.4$ people. Workers with secondary education are the majority (66.7\%). The average number of years of work in slaughterhouses in Brazzaville is $18.9 \pm$ 9.5 years. The survey also showed that many workers, $52.6 \%$, have never received training to work in slaughterhouses. A tier of workers (31.7\%) have no knowledge of animal tuberculosis, in particular its modes of transmission or its clinical signs. The premises are; normal, regularly cleaned, but are not disinfected. Despite the common occurrence of injuries, $73.7 \%$ of those surveyed said that they were not subjected to medical checks. To this, we must add, the lack of work clothes adapted by some (29.8\%). All of these shortcomings constitute significant risks of contamination from zoonoses, and tuberculosis in particular. Thus, the study recommends strengthening the capacities of professionals in slaughterhouses, their medical follow-up and improve infrastructure. Finally, the fight against zoonotic tuberculosis requires a multisectoral framework involving doctors and veterinarians in the context of the "One Health" approach.

\section{Background}

Tuberculosis (TB) remains a global public health problem (1) and a major scourge to livestock. Mycobacterium bovis belong to the $M$. tuberculosis complex with cattle being the most important reservoir. Firstly, it causes serious illness in humans and many animal species, thus plays a central role in public health (2). Secondly, significant economic losses for cattle producers linked to herds affected by tuberculosis and cattle, remain critical point in animal health (3). Zoonotic tuberculosis is an important public health disease, but it has long been neglected (4). The bacteria responsible are two different organisms which are now known as Mycobacterium tuberculosis and Mycobacterium bovis $(4,5)$.

Tuberculosis is caused by Mycobacterium tuberculosis in humans resulting in active TB (6) in and $M$. bovis in cattle with a broader host range for TB in domestic and wild animals $(7,8)$. In addition, $M$. bovis infects humans, causing zoonotic TB in humans (9).

Studies have shown cases of transmission of tuberculosis from infected cattle to humans (10). In January 2017 and June 2018 bovine tuberculosis occurs in 82 of the 188 member countries of the World Organization for Animal Health, that is, 44\% (11). In 2016, according to WHO estimates, 147,000 new cases of zoonotic tuberculosis were reported in humans with 12,500 deaths (12). Bovine tuberculosis destroys livelihoods and is hampering efforts to achieve the "End TB" Strategy goal of tuberculosis elimination by 2030 (13). 
In developed countries, the cases of human Mycobacterium bovis are less and less reported, thanks to the campaign of eradication bovin TB and the strict application of food safety standard, notably the pasteurization of milk. The strict systematic eradication of contaminated cattle, whereas in developing countries, bovine tuberculosis causes significant losses in the cattle industry, with serious consequences for public health $(14,15)$. According to Olea-Popelka et al., (2017), the proposition of human TB from bovine origin, could represent up to $30 \%$ of human TB cases. (9).

Transmission of bovine TB from infected cattle to humans occurs primarily through consumption of raw (unpasteurized) milk or raw milk products containing the bacteria (16). Transmission can also occur through prolonged exposure to bacteria in the air in the immediate vicinity of live infected cattle or their carcasses (17). On rare occasions, bovine TB is passed to a human when bacteria from the infected animal get into a cut on a person's skin (18).

In sub-Saharan Africa, the work carried out made it possible to isolate Mycobacterium bovis in $16 \%$ of human patients with tuberculosis according to the studies carried out by Boukary et al., (19). Man becomes infected by consuming raw dairy products or undercooked meats from infected cows, inhaling infectious droplets or by close contact with tuberculous animals or virulent materials (meat, lymph nodes, blood, discarding, saliva, sputum, feces, urine, and pus from skin lesions, uterine secretions, and sperm). Infected cattle therefore pose a risk to public health (20). Slaughterhouses are places of human-animal interface with potential risks of contamination of professionals by various zoonotic diseases. It is through injury from contaminated instruments that there is a risk of infection. In Mexico, $6 \%$ of slaughterhouse workers have shown a spoligotype of Mycobacterium bovis (21).

In Nigeria, a retrospective study carried out at the Jos slaughterhouse in the Plateau State obtained a prevalence of TB infection in cattle of $12 \%$, with a real prevalence in the population of $6 \%$ (Cl of $95 \%$ from 3.8 to 8.1) (Okeke et al., 2016). Similar study was carried out in Benin, RDC, and Cameroon.

Although risk factors vary across regions due to different farm structures and farm management practices (22-24). Other risk factors include the use of manure, artificial fertilize, covered housing for animals, cattle buying practices and the prevalence of bovine TB (25). A study revealed many risk factors in humans which is related to poverty and are very difficult to address. Risk factors for cattle include historical TB on a farm, movement of animals, TB on neighboring property or in wildlife in contact with domestic stock, prevalence of TB in a herd or area and herd size, multiple premises, poor housing, and nutrition (26).

Currently, Brazzaville does not have a functional municipal slaughterhouse and few studies have been carried out on slaughterhouses with regard to animal tuberculosis, particularly bovine tuberculosis. Studies on animal TB, notably bovine are rare as well as the implication of human TB in professional abattoirs Congo. The objective of this present study is to characterize the occupational exposure of slaughterhouse workers to the risks of contamination from zoonotic tuberculosis due to Mycobacterium bovis. 


\section{Methods}

\section{Period and type of study}

This is a descriptive exploratory study, using qualitative and quantitative methods and tools, carried out between August and December 2019. The slaughterhouse workers were questioned and their practices observed along the chain of transforming animals into meat.

\section{Study area}

This study was done at the slaughterhouses in the center of the city located in Brazzaville, the political capital of the Republic of Congo. It is the largest and highest region with the consumption of fresh beef. Brazzaville is located in the south of the country, on the right bank of the Congo River. It stretches over $110 \mathrm{~km}$ and has nearly $2,000,000$ inhabitants, or $33 \%$ of the total Congolese population. It is the largest consumption center and in particular that of fresh beef. It is subdivided into 9 "arrondissements" or subdivision: Makélékélé, Bacongo, Poto-poto, Moungali, Ouénzé, Talangaî, Mfilou, Madibou and Djiri.

\section{Study sites}

The study sites chosen are animal slaughterhouses. A slaughterhouse is any establishment approved by the competent authority, used for the slaughter and dressing of animals intended for human consumption while subjecting them to a health inspection. It employs many professionals (butchers, cutters, skinners, weighing technicians, traders, breeders, transporters, etc.). As Brazzaville does not have a modern municipal slaughterhouse, three large functional animal slaughtering sites (all belonging to private economic operators) have been selected: the Mpila and the Kanga Mbanzi slaughterhouse located in the Talangai district, and the Fern slaughterhouse located in the Makélékélé district, whose characteristics are given in Table 1. The Mpila slaughterhouse is the largest in terms of area and number of animals slaughtered daily.

Table 1

Characteristics of different slaughterhouses in Brazzaville

\begin{tabular}{|llll|}
\hline Slaughterhouse & $\begin{array}{l}\text { Number of animals slaughtered per } \\
\text { day }\end{array}$ & $\begin{array}{l}\text { Staff working on } \\
\text { site }\end{array}$ & $\begin{array}{l}\text { Surface area } \\
\left(\mathrm{m}^{2)}\right.\end{array}$ \\
\hline Mpila & $8-12$ & $30-60$ & 1600 \\
\hline Kanga Mbanzi & $3-4$ & $10-15$ & 300 \\
\hline La Fougère & $2-3$ & $8-12$ & 300 \\
\hline
\end{tabular}

\section{Sampling method and sample population}


The target population was made up of all those working in the three slaughterhouses, whatever the function (slaughter, cutters, butchers, weighers, butchers, merchants, breeders, transporters, etc.). Not knowing the total population size, it was decided to use a sampling method which does not require an exhaustive census of individuals. All the workers who met the inclusion criteria were retained.

\section{Survey method}

The survey was carried out using simple questionnaires (see annex) during oral interviews in national languages (Lingala and Kituba) or in French with the people concerned by the study. The researchers conducted risk assessments of the study to avoid dangers to all individuals and animals involved in the project.

The interviews took place from 6 am, after animals were slaughtered and the staff released from their professional duties. The duration of each interview was approximately 10 minutes. In addition to the interviews, direct observations were made and noted to obtain additional information on the phenomenon under study. Risk factors for zoonotic bovine tuberculosis infection in cattle producers were examined by a questionnaire conducted to collect information on a range of lifestyle and consciousness. Variables from 57 randomly selected participants from the three slaughterhouses were listed and the participants were chosen by allocation of random numbers.

\section{Data analysis}

Raw data was introduced into Epi-Info (version 6, WHO) and SPSS to generate frequency distributions of bovine tuberculosis while the Chi-square test was used to assess the association between risk factors for zoonotic bovine tuberculosis infection. Data expressed as frequencies and percentages, unless otherwise indicated. The distribution of infection in different groups was compared by Chi-square or Fisher Exact Test.

The variation between the different factors evaluated using Chi-square (X2) and all the statistical analyzes carried out by the statistical software SPSS version 25. Tables and bar graphs were constructed using Microsoft Excel 2010. The P-value of 0.05 and the 95\% confidence level were used for statistical significance.

\section{Ethical considerations}

This study was submitted to the institutional ethics committee of the Fondation Congolaise pour la Recherche Médicale (FCRM) and received the ethical clearance (CEIFCRM/2403/00). This research work was conducted according to the principles of the World Organisation for Animal Health (OIE) on the use of animals in research and education. Whenever possible, we prevent, relieve and minimize pain, suffering and distress, and improve the welfare of animals used for research during the ant autopsy. 
As a prelude to the start of the activities, authorizations were obtained from municipal and ministerial authorities, and exchange meetings were organized with the slaughterhouse managers in order to explain the objectives of the study and to obtain their support and their free and informed consent. A written informed consent (validated by the institutional ethics committee of the FCRM) was obtained from each participant before to be enrolled in the study and filling the form. The confidentiality of data collected was ensured. In addition, the results of the study will be returned to them with practical advice to prevent cases of possible human contamination.

\section{Results}

Among the survey of 57 people working in the three slaughterhouses in Brazzaville, the Mpila slaughterhouse is the largest with the greatest human resource capacity.

\section{Profile of slaughterhouse workers}

Men are the most numerous and 29 (50.9\%) of them are over 40 years old. Married workers represented $29.8 \%$ and lived in families of 4.9 to 2.4 people. The survey found $40(70.2 \%)$ single, the majority of high school students having the majority among the dominant employees was 38 (66.7\%). There were 34 $(59.7 \%)$ of employees who reported living with at least 6 people in their home (Table 2). 
Table 2

Profile of Staff working at slaughterhouses in Brazzaville

\begin{tabular}{|c|c|}
\hline Variables & Number (\%) \\
\hline Total Number & 57 \\
\hline \multicolumn{2}{|l|}{ Gender $\mathrm{n}(\%)$} \\
\hline Male & $55(96.5)$ \\
\hline Feminine & 02(03.5) \\
\hline \multicolumn{2}{|l|}{ Age $n(\%)$} \\
\hline$\leq 20$ years & $00(0.0)$ \\
\hline 21 - 40 years old & $28(49.1)$ \\
\hline 40 years & $29(50.9)$ \\
\hline Medium \pm Standard deviation & $40.6 \pm 8.4$ \\
\hline \multicolumn{2}{|l|}{ Marital status n (\%) } \\
\hline Married & 17(29.8) \\
\hline Single & $40(70.2)$ \\
\hline \multicolumn{2}{|l|}{ Level of education $\mathrm{n}(\%)$} \\
\hline \multicolumn{2}{|l|}{ Primary } \\
\hline Secondary & \\
\hline Superior & $\begin{array}{l}38(66.7) \\
01(01.7)\end{array}$ \\
\hline \multicolumn{2}{|c|}{ Number of people at employee's household $\mathrm{n}(\%)$} \\
\hline$\leq 3$ & $15(26.3)$ \\
\hline $4-6$ & $34(59.7)$ \\
\hline$\nabla 6$ & $08(14.0)$ \\
\hline Medium \pm Standard deviation & $4.9 \pm 2.4$ \\
\hline
\end{tabular}




\section{Slaughter practices}

On average, the number of years of practice was around 19 years, so that $50 \%$ of workers already had 21 years of work experience. Only $27(47.4 \%)$ of the workers who declared having undergone training for this activity and $40(70.2 \%)$ adequate equipment (Table 3$)$. During their activity, the workers of the slaughterhouse wear a variety of outfits.

Table 3

Slaughter practices

\begin{tabular}{|lc|}
\hline Variables & Number (\%) \\
\hline Number of years of practice (Experience) & \\
Medium \pm Standard deviation & $18.9 \pm 9.5$ \\
Median (Min - Max) & $21(2-40)$ \\
Have undergone training for this activity n(\%) & \\
No & $30(52.6)$ \\
Yes & $27(47.4)$ \\
& \\
Availability of appropriate equipment & \\
No & $17(29.8)$ \\
Yes & $40(70.2)$ \\
\hline
\end{tabular}

\section{Hygiene and health of workers}

The three slaughter areas (Mpila, Kanga Mbanzi and La Fougère) are supplied with running water for the regular cleaning of animal carcasses, equipment and premises. All workers owned 40 boots $(100 \%)$ with regard to other equipment, the possession of work overalls and pants with shirt, were 28 (70\%) and 31 (77.1\%) respectively.

With regard to hygiene and health of workers, the number of times the cleaning of clothes per week was carried out, was $3.9 \pm 1.8$. A total of $55(96.5 \%)$ employees took a bath after work and all $57(100 \%)$ reported cleaning their work premises. Almost all 56 employees (98.2\%) have already had an injury at work, but only $15(26.3 \%)$ have had health visits and 38 (66.7\%) have been vaccinated (Table 4$)$. 
Variables

Mean \pm Standard deviation

$3.9 \pm 1.8$

Average number of work clothes cleaning per week (min - max) $3(1-7)$

Bath after work $\mathrm{n}(\%)$

No $55(96.5)$

Yes

Cleaning of work premises $\mathrm{n}(\%)$

0

No

Yes

$1.3(1-2)$

Have you done health care visits $n(\%)$

No

42(73.7)

Yes

15(26.3)

Have you been vaccinated $n(\%)$

No

Yes

38(66.7)

Have you got injury at work $\mathrm{n}(\%)$

No

Yes

\section{Knowledge about tuberculosis and health risks}


$31.7 \%$ of workers had no knowledge of bovine tuberculosis, including the mode of transmission and clinical signs. However, more than $70 \%$ of them admitted to having been informed of the risks of contamination of the diseases by the veterinarian in charge of their slaughterhouse (Table 5).

Table 5

Knowledge about tuberculosis and associated health risks

\begin{tabular}{|ll|}
\hline Variables & Effectives \\
Ko & \\
Yes & $13(31.7)$ \\
Have you been made aware of risk $n(\%)$ & $\mathbf{2 8}(68.3)$ \\
No & \\
Yes & $17(29.8)$ \\
If yes, by whom & $\mathbf{4 0}(70.2)$ \\
Veterinary & \\
Others & $\mathbf{4 0}(100)$ \\
& 0 \\
Have you heard of tuberculosis in animals & \\
No & $16(71,1)$ \\
Yes & $\mathbf{4 1}(28,1)$ \\
\hline
\end{tabular}

Only 28 (68.3\%) of the workers at the three slaughterhouses were aware of the modes of TB transmission. Those who were made aware of the risk of contamination represented only $70.2 \%$, this awareness was only made by the veterinarians responsible for their slaughterhouse 40 (100\%). 41 (28.1\%) employees had heard of tuberculosis in animals (Table 5). Cough and inflammation of the lymph nodes and cough, including the two symptoms of bovine tuberculosis most cited by employees aged 13 (31.7\%) and $25(60.9 \%)$.

Very few surveys have been carried out among slaughterhouse workers on the risks of contamination by tuberculosis in the Republic of Congo. There are many risk factors for contamination of slaughterhouse personnel, including risks related to the profile of personnel, the condition of slaughter structures, and slaughter practices.

Slaughterhouse staff are mainly made up of people over 40 (50.9\%). Women are only $3.5 \%$ of the workers, which is likely related to selflessness or the risk of injury. Workers with secondary education were 
the majority in the analysis (66.7\%), opening up the prospect of capacity building.

Zoonoses, including tuberculosis, are frequently detected during slaughter $(15,27,28)$. However, those with a low level of education hardly perceive the microbiological dangers linked to their activities.

The knowledge, attitudes, practices and beliefs of slaughterers are largely insufficient for their profession, given the important role they play in public health and the community. Many of them (52.6\%) have never received training in animal pathologies and good hygiene practices. Ignorance of zoonotic tuberculosis by almost a third of workers $(31.7 \%)$ is a cause for concern. The work exposes them to the microbiological dangers linked to Mycobacterium bovis without knowing it. Unlike the survey of 300 slaughterhouse workers in the cities of Bishoftu, Modjo, Dukem and Akaki, in central Ethiopia where TB was known by about $95 \%$ of workers (29).

About $34 \%$ of the respondents live in relatively large families, made up of 4 to 6 members, who, if infected with TB, can in turn come in contacts with family members. The slaughterhouses of Mpila, Kanga Mbanzi and La Fougère do not meet the minimum technical standards, thus need to be closed. These slaughter areas, even paved and covered, do not meet the minimum technical standards required for the slaughtering of animals in good hygienic conditions for meat and staff. An FAO survey after an inventory of slaughterhouses for slaughter animals in Central Africa (30). Slaughtering operations, ranging from restraint of the animal to evisceration through sanitary control, are risks for abattoir workers. Contact with tuberculous lesions is then possible (31). The circumstances of exposure to a tuberculosis animal in a slaughterhouse often result from a situation of incidental discovery of suspicious lesions (32). Some carcasses have forms of tuberculosis in the form of broken lesions on one or more lymph nodes (17).

During our investigation, we observed that the operations of bleeding, butchering and evisceration of animals for slaughter in the field, good hygiene practices are not applied.

Improved hygiene conditions are associated with the level of health education and awareness of operational staff who come into direct contact with meat: butchers, transporters and retail butchers. To this must be added the lack of suitable work clothing by some $(29.8 \%)$.

Studies have shown that while working in slaughterhouses, workers are covered in blood and cattle droppings with the potential risk of contamination (33-36). The use of an apron, waterproof gloves and the wearing of a visor would limit the circumstances of accidental contact with the skin.

The prevalence of cattle in the Republic of Congo is not known. In Central Africa, studies have confirmed the presence of bovine tuberculosis in proportions of $4.3 \%$, in Cameroon, $10.3 \%$ in Chad (37) and $5.74 \%$ in the DRC (38).

Vaccination and health checks are not very common among workers. However, during slaughter operations, almost all respondents (98.2\%) said that they had suffered knife wounds, with the risk that the contaminated knife would be in direct contact with a tuberculosis lesion. 
The working time of workers in slaughterhouses also constitutes the period of exposure to possible infections. The average duration of the workers' exercise was considerable, thus favorable to the risks of contamination by tuberculosis and other zoonoses $(4,39)$. A study in Nigeria found a correlation between the duration of exposure and the degree of risk of contamination by different zoonotic germs (20).

Infected cattle pose a risk to public health; previous studies have revealed the role of Mycobacterium bovis in the transmission of pulmonary tuberculosis from cattle to humans (39). Tuberculosis screening was not carried out at the level of the slaughterhouse workers interviewed, but certain studies have highlighted the contamination of professionals working in cattle breeding $(4,17,40)$.

\section{Conclusion}

Bovine zoonotic tuberculosis is also an occupational disease (4). At the slaughterhouse level, the risk of contamination stems from direct contact between workers and diseased cattle (30) or their products during the slaughter of animals and the preparation of carcasses (20). The poor condition of slaughterhouses, the lack of training in worker hygiene and medical control, the lack of staff clothing, the incomplete cleaning and disinfection of premises and equipment are all risk factors favoring tuberculosis at work.

In light of these results of this survey, it is necessary to:

- schedule regular training for slaughterhouse staff on zoonoses and good hygiene practices;

- provide professionals with appropriate personal protective equipment to protect themselves from blood and other animal tissues;

- check the health of staff by means of an annual examination;

- improve structures by building a modern slaughterhouse;

The fight against bovine zoonotic tuberculosis is an essential necessity in a multi-confessional setting. The involvement of veterinarians in the context of the "One Health" approach must be increasingly developed in our country. It should be about raising awareness among key players, including drawing more attention on clinical and physical signs.

\section{Abbreviations}

TB: Tuberculosis

\section{M.: Mycobacterium}

DRC: Democratic Republic of Congo

FAO: Food and Agriculture Organization

OIE: World Organization for Animal Health 


\section{Declarations}

\section{Consent for publication}

All the authors agree for this submission and publication.

\section{Availability of data and material}

Data will be made available upon request .

\section{Competing interests}

No competing interest was declared.

\section{Funding}

This study received support of the PANDORA-ID-NET consortium grant, funded by the European and Developing Countries Clinical Trials Partnership (EDCTP-2) program (EDCTP Reg/Grant RIA2016E-1609), which is supported under 'Horizon 2020, the European Union's framework program for research and innovation. FN is member of PANDORA-ID-Net (Reg/Grant RIA2016E-1609) and CANTAM (Central Africa clinical Research Network) (EDCTP-RegNet2015-1045) .

\section{Author contributions}

FN and JPM conceived the study. PI and JPM participated in study design, performed the experiments and wrote the manuscript. LSGL, GA and BTF supervised the molecular genetic study. GA, LN, HGK reviewed and edited the manuscript. All authors approved the final version of the manuscript.

\section{Acknowledgement}

We do thank all the participants for their valuable contribution to this work.

\section{References}


1. UNAIDS. Innovative and people-empowered approaches to end TB deaths [Internet]. GENEVE: UNAIDS. https://www.unaids.org/en/keywords/tuberculosis-tb (2020). Accessed 20 May 2020.

2. Nathavitharana RR, Bond P, Dramowski A, Kotze K, Lederer P, Oxley I, et al. Agents of change: The role of healthcare workers in the prevention of nosocomial and occupational tuberculosis. Presse Medicale Paris Fr 1983. 2017 Mar;46(2 Pt 2):e53-62.

3. Gormley E, Corner LAL. Wild Animal Tuberculosis: Stakeholder Value Systems and Management of Disease. Front Vet Sci. 2018;5:327.

4. N. Teppawar R, P. Chaudhari S, L. Moon S, V. Shinde S, A. Khan W, R. Patil A. Zoonotic Tuberculosis: A Concern and Strategies to Combat. In: Enany S, editor. Basic Biology and Applications of Actinobacteria [Internet]. IntechOpen; https://www.intechopen.com/books/basic-biology-andapplications-of-actinobacteria/zoonotic-tuberculosis-a-concern-and-strategies-to-combat. (2020). Accessed 16 May 2020

5. Inlamea OF, Soares P, Ikuta CY, Heinemann MB, Achá SJ, Machado A, et al. Evolutionary analysis of Mycobacterium bovis genotypes across Africa suggests co-evolution with livestock and humans. Yang R, editor. PLoS Negl Trop Dis. 2020 Mar 2;14(3):e0008081.

6. Jilani TN, Avula A, Zafar Gondal A, Siddiqui AH. Active Tuberculosis. In: StatPearls [Internet]. Treasure Island (FL): StatPearls Publishing; http://www.ncbi.nlm.nih.gov/books/NBK513246/. (2020). Accessed 26 May 2020.

7. Mohamed A. Bovine tuberculosis at the human-livestock-wildlife interface and its control through one health approach in the Ethiopian Somali Pastoralists: A review. One Health. 2020 Jun;9:100113.

8. Gormley E, Corner LAL. Pathogenesis of Mycobacterium bovis Infection: the Badger Model As a Paradigm for Understanding Tuberculosis in Animals. Front Vet Sci. 2018 Jan 15;4:247.

9. Olea-Popelka F, Muwonge A, Perera A, Dean AS, Mumford E, Erlacher-Vindel E, et al. Zoonotic tuberculosis in human beings caused by Mycobacterium bovis -a call for action. Lancet Infect Dis. 2017 Jan;17(1):e21-5.

10. Hlokwe TM, Said H, Gcebe N. Mycobacterium tuberculosis infection in cattle from the Eastern Cape Province of South Africa. BMC Vet Res. 2017 Dec;13(1):299.

11. Palmer MV. Mycobacterium bovis: Characteristics of Wildlife Reservoir Hosts. Transbound Emerg Dis. 2013 Nov;60:1-13.

12. WHO. - Global Tuberculosis Report [Internet]. GENEVE: WHO; 2017 [cited 2020 May 26]. Available from: https://www.who.int/tb/zoonoticTB.pdf

13. WHO. The challenges of preventing bovine tuberculosis. Bull World Health Organ. 2018 Feb 1;96(2):82-3.

14. Kemal J, Sibhat B, Abraham A, Terefe Y, Tulu KT, Welay K, et al. Bovine tuberculosis in eastern Ethiopia: prevalence, risk factors and its public health importance. BMC Infect Dis. 2019 Jan 10;19(1):39. 
15. Vikou R, Aplogan LG, Ahanhanzo C, Baba-Moussa L, Gbangboche AB. Prévalence de la brucellose et de la tuberculose chez les bovins au Bénin. Int J Biol Chem Sci. 2018 Jun 1;12(1):120.

16. Bolaños CAD, Paula CL de, Guerra ST, Franco MMJ, Ribeiro MG. Diagnosis of mycobacteria in bovine milk: an overview. Rev Inst Med Trop Sao Paulo. 2017 Jun 5;59:e40.

17. K.N. Kuria J. Diseases Caused by Bacteria in Cattle: Tuberculosis. In: Abdel hay El-Sayed Kaoud H, editor. Bacterial Cattle Diseases [Internet]. https://www.intechopen.com/books/bacterial-cattlediseases/diseases-caused-by-bacteria-in-cattle-tuberculosis. (2019). Accessed 26 May 2020

18. Abakar MF, Yahyaoui Azami H, Justus Bless P, Crump L, Lohmann P, Laager M, et al. Transmission dynamics and elimination potential of zoonotic tuberculosis in morocco. Petersen CA, editor. PLoS Negl Trop Dis. 2017 Feb 2;11(2):e0005214.

19. Malama S, Johansen TB, Muma JB, Munyeme M, Mbulo G, Muwonge A, et al. Characterization of Mycobacterium bovis from Humans and Cattle in Namwala District, Zambia. Vet Med Int. 2014;2014:1-7.

20. Sa'idu AS, Okolocha EC, Dzikwi AA, Gamawa AA, Ibrahim S, Kwaga JKP, et al. Public Health Implications and Risk Factors Assessment of Mycobacterium bovis Infections among Abattoir Personnel in Bauchi State, Nigeria. J Vet Med. 2015;2015:1-5.

21. Milián-Suazo F, Pérez-Guerrero L, Arriaga-Díaz C, Escartín-Chávez M. Molecular epidemiology of human cases of tuberculosis by Mycobacterium bovis in Mexico. Prev Vet Med. 2010 Oct;97(1):3744.

22. Mekonnen GA, Conlan AJK, Berg S, Ayele BT, Alemu A, Guta S, et al. Prevalence of bovine tuberculosis and its associated risk factors in the emerging dairy belts of regional cities in Ethiopia. Prev Vet Med. 2019 Jul;168:81-9.

23. Bouchez-Zacria M, Courcoul A, Durand B. The Distribution of Bovine Tuberculosis in Cattle Farms Is Linked to Cattle Trade and Badger-Mediated Contact Networks in South-Western France, 2007-2015. Front Vet Sci. 2018 Jul 26;5:173.

24. Dejene SW, Heitkönig IMA, Prins HHT, Lemma FA, Mekonnen DA, Alemu ZE, et al. Risk Factors for Bovine Tuberculosis (bTB) in Cattle in Ethiopia. Sreevatsan S, editor. PLOS ONE. $2016 \mathrm{Jul}$ 12;11(7):e0159083.

25. McAloon CG, Doherty ML, Whyte P, More SJ, O'Grady L, Citer L, et al. Relative importance of herd-level risk factors for probability of infection with paratuberculosis in Irish dairy herds. J Dairy Sci. 2017 Nov;100(11):9245-57.

26. Skuce RA, Allen AR, McDowell SWJ. Herd-Level Risk Factors for Bovine Tuberculosis: A Literature Review. Vet Med Int. 2012;2012:1-10.

27. Okeke E, Dingsdale H, Parker T, Voronina S, Tepikin AV. Endoplasmic reticulum-plasma membrane junctions: structure, function and dynamics: Endoplasmic reticulum-plasma membrane junctions. $J$ Physiol. 2016 Jun 1;594(11):2837-47.

28. Romha G, Gebru G, Asefa A, Mamo G. Epidemiology of Mycobacterium bovis and Mycobacterium tuberculosis in animals: Transmission dynamics and control challenges of zoonotic TB in Ethiopia. 
Prev Vet Med. 2018 Oct;158:1-17.

29. Fekadu F, Beyene TJ, Beyi AF, Edao BM, Tufa TB, Woldemariyam FT, et al. Risk Perceptions and Protective Behaviors Toward Bovine Tuberculosis Among Abattoir and Butcher Workers in Ethiopia. Front Vet Sci. 2018 Jul 24;5:169.

30. Allan KJ, Halliday JEB, Moseley M, Carter RW, Ahmed A, Goris MGA, et al. Assessment of animal hosts of pathogenic Leptospira in northern Tanzania. Foley J, editor. PLoS Negl Trop Dis. 2018 Jun 7;12(6):e0006444.

31. Sharma S, Bajpai J, Pathak PK, Pradhan A, Singh P, Kant S. Oral tuberculosis - Current concepts. J Fam Med Prim Care. 2019 Apr;8(4):1308-12.

32. McKinley TJ, Lipschutz-Powell D, Mitchell AP, Wood JLN, Conlan AJK. Risk factors and variations in detection of new bovine tuberculosis breakdowns via slaughterhouse surveillance in Great Britain. de Boer WF, editor. PLOS ONE. 2018 Jun 8;13(6):e0198760.

33. Amemor EA, Sackey SO, Yebuah N, Folitse RD, Emikpe BO, Afari E, et al. The prevalence of tuberculosis in cattle and their hankers in North Tongu, Volta egion, Ghana. Afr J Infect Dis. 2017;11(1):12-7.

34. Chauhan AS, George MS, Lindahl J, Grace D, Kakkar M. Community, system and policy level drivers of bovine tuberculosis in smallholder periurban dairy farms in India: a qualitative enquiry. BMC Public Health. 2019 Dec;19(1):301.

35. van der Heijden EMDL, Cooper DV, Rutten VPMG, Michel AL. Mycobacterium bovis prevalence affects the performance of a commercial serological assay for bovine tuberculosis in African buffaloes. Comp Immunol Microbiol Infect Dis. 2020 Jun;70:101369.

36. Salifou C, Youssao A, Salifou S, Kpodekon T, Tougan P, Ahounou G, et al. Evaluation du procédé d'abattage des bovins aux abattoirs de Cotonou-Porto- Novo au sud du Bénin. Int J Biol Chem Sci. 2013 May 8;6(6):6049-61.

37. Awah Ndukum J, Kudi AC, Bradley G, Ane-Anyangwe IN, Fon-Tebug S, Tchoumboue J. Prevalence of Bovine Tuberculosis in Abattoirs of the Littoral and Western Highland Regions of Cameroon: A Cause for Public Health Concern. Vet Med Int. 2010:1-8.

38. Telamanu BE, Nzashilumengu Al, Ngulu-Nsasi A. . Causes de mortalité bovine au secteur Izeli du ranch de Mushie en République Démocratique du Congo. Rev Mar Sci Agron Vét. 2019;7(3):458-62.

39. Adesokan HK, Akinseye VO, Streicher EM, Van Helden P, Warren RM, Cadmus SI. Reverse zoonotic tuberculosis transmission from an emerging Uganda I strain between pastoralists and cattle in South-Eastern Nigeria. BMC Vet Res. 2019 Dec;15(1):437.

40. Phipps E, McPhedran K, Edwards D, Russell K, O’Connor CM, Gunn-Moore DA, et al. Bovine tuberculosis in working foxhounds: lessons learned from a complex public health investigation. Epidemiol Infect. 2018 Oct 9;1-6. 